\title{
On oxidation by means of cyanogen
}

\section{M.P.C. Boudault}

To cite this article: M.P.C. Boudault (1845) On oxidation by means of cyanogen, Philosophical Magazine Series 3, 27:180, 307-308, DOI: 10.1080/14786444508645283

To link to this article: http://dx.doi.org/10.1080/14786444508645283

曲 Published online: 30 Apr 2009.

Submit your article to this journal

Џ Article views: 2

Q View related articles $₫$ 
obtained in numbers (free from theoretical objection), and capable of having the probable error computed, it should be adopted until something better can be advanced.

"It will not do for any one to tell the public, even in the case of the magnitudes of stars, that ' he has tried all instrumental methods, and found all to be inferior to estimation by the naked eye ;' because, so long as such a method of observation is the only one followed, so long will the assertion remain mere rhetoric, - a consumption of time without producing its equivalent of useful effect. Let us rather remember the primary and aphorismal foundations of practical science, such as :-

" 'Science begins with the observation of common facts, but, even at this stage, requires that the observations be precise.'

" 'Facts are the materials of science, but all facts involve ideas, and since in observing facts we cannot exclude ideas, we must take care that for the purposes of science, the ideas be clear and vigorously applied. Therefore, facts for the purposes of material science, should involve conceptions of the intellect only, and not emotions, and must be observed with reference to our most exact conceptions, number, place, figure, motion, force, \&c." "

\section{Intelligence and Miscellaneous Articles. ON OXIDATION BY MEANS OF CYANOGEN. BY M. P. C. BOUDAULT.}

\section{$\mathbf{T}$}

THE author observes that chlorine, bromine and iodine are not the only bodies which possess oxidizing power by indirect action; and he shows that cyanogen, which has been proved to act in many cases as an elementary body, is also susceptible of effecting oxidizement.

The instability of cyanogen, when dissolved in water, always appeared to offer an obstacle to the author's proposed researches on this subject; it therefore occurred to him to replace cyanogen by a compound, in which this body was in loose combination, or, so to express it, in a mobile condition, that it might readily act upon oxygenated compounds, and separate their oxygen; and these conditions appeared to be fulfilled by the ferridcyanide of potassium, or red prussiate of potash. This salt, when heated out of the contact of air, is decomposed into nitrogen, cyanogen, ferrocyanide of potassium, cyanide of potassium and carburet of iron; but when decomposed in air it yields peroxide of iron and more cyanogen. It appeared therefore to the author that this compound might yield a portion of its cyanogen by certain acid reactions; and this was found to be the case.

When the equivalent of potassium, which chlorine removes from ferrocyanide of potassium to convert it into ferridcyanide, is added to it, no reaction takes place between them, even in a month, at ordinary temperatures; but when boiled and concentrated, peroxide of iron is precipitated, cyanide and ferrocyanide of potassium are formed, but no oxygen is obtained.

\section{$\mathrm{X} 2$}


The author concluded that the decomposition of ferridcyanide into ferrocyanide, would afford cyanogen which would act as if it were free; and he found that when he heatec oxide of lead in a mixture of ferridcyanide and potash, he procured binoxide of lead, and the solution contained ferrocyanide of potassium only. Having thus proved that the ferridcyanide might be substituted for cyanogen as an oxidizing agent, experiments were performed on the superoxidizement of various oxides.-Journ. de Pharm. et de Ch., Juin 1845.

\section{SUPEROXIDIZEMENT OF METALLIC OXIDES BY MEANS OF THE FERRIDCYANIDE OF POTASSIUM. BY M. BOUDAULT.}

The author remarks, that metallic oxides in general have a tendency to pass to a higher degree of oxidizement; and some of them undergo it with great readiness, under the oxidizing influence of cyanogen, either at common temperatures or when boiling, according as the oxide is more or less superoxidizable.

Oxide of Manganese.-When protoxide of manganese, which has been precipitated without the contact of air, or a salt containing this oxide, is added to a mixed solution of cold ferridcyanide of potassium and potash, there are immediately obtained peroxide of manganese and ferrocyanide of potassium : with a large quantity of potash, crystallized peroxide of manganese was formed. If, instead of adding an excess of ferridcyanide, an excess of a salt of manganese be employed with a large quantity of potash, a reddish-brown precipitate may be obtained, which is probably the manganoso-manganic oxide.

Oxide of Nickel and Oxide of Cobalt.-The protoxide of nickel, when added to an alkaline solution of the red salt, does not appear to be superoxidized; and if it be boiled for some time decomposition occurs unconnected with oxidizement.

The same is the case with oxide of cobalt; there occurs, nevertheless, a moment in which the oxide of cobalt seems to be superoxidized, but it is probably reduced by the ferrocyanide which is formed.

Oxide of Lead.-The superoxidation of lead is the most marked of any oxide; a salt of oxide of lead, or the oxide itself, when dissolved in potash, is converted into binoxide, and almost always precipitated in the crystalline state; this latter fact, however, appears to depend upon the quantity of potash employed. On some occasions the author obtained minium by employing excess of the salt of lead, and heating the liquor but slightly.

Oxide of Copper.-The ferridcyanide of copper, or the oxide, are superoxidized by the mixed solution of ferridcyanide of potassium and potash ; there are obtained a black precipitate, and ferrocyanide as usual.

Oxide of Tin.-The salts of protoxide of tin effect a reduction of the ferridcyanide, which indicates superoxidizement; but the author could not ascertain the nature of the oxide which is precipitated. 